\title{
LA SEMIOSIS TEXTUAL Y EL MODELO PEIRCEANO
}

\author{
Carmen Vlad \\ Universidad Babeș - Bolyai (Cluj)
}

\begin{abstract}
Lo indescriptible, lo inefable, lo incomprensible provocan de costumbre gran emoción; nada es sin embargo tan tranquilizador como una explicación científica (Peirce, C. P. 5.292).
\end{abstract}

\section{EL TEXTO COMO SIGNO}

La cada vez mayor fascinación por los signos, como consecuencia de una mayor conciencia sígnica, me parece ser una característica de la etapa cultural que estamos atravesando. Los comienzos de esta conciencia se encuentran en la antigüedad, en Platón («el nombre - decía el filósofo en sus diálogos socráticos- es un instrumento proveedor de aprendizaje y discriminador de la naturaleza de las cosas», Opere, III 1979: 258) y luego en Aristóteles, que descubría en el habla la modalidad humana de conocer la realidad, de enfrentarse a ella. 
A lo largo de un itinerario marcado por «la civilización del libro» (como fue llamada la época moderna de la cultura, surgida después del Renacimiento), pasando por el período de la «civilización de la imagen» dominante en la mitad de nuestro siglo (véase la demostración de René Huyghe en 1965, Les puissances de l'image), la historia de la civilización parece consumir bajo nuestras miradas su momento sígnico.

La dependencia del pensamiento científico de las formas simbólicas, con un fuerte eco y con efectos sensibles en la epistemología contemporánea, ha encontrado en el pensamiento de Ch. S. Peirce una de las más concisas expresiones: «La lógica, en su sentido general, [...] no es más que otro nombre para la semiótica, doctrina casi necesaria o formal de los signos». Estos últimos representan un instrumento básico, indisolublemente relacionado con la inteligencia humana «científica», es decir, by an intelligence capable of learning by experience (Peirce, 2: 227).

Se ha producido una nueva resurrección de la óptica semiótica en la investigación verbal, junto con el asumir el texto como objeto sumiso a la verificación. El valor semiótico de éste ya no se atribuye sólo a la naturaleza sígnica de sus unidades verbales de rango inferior: morfemas, palabras, oraciones/frases (según un razonamiento del tipo: $\mathbf{s i} \mathbf{a}=$ signo y $\mathrm{b}=$ signo, entonces $\mathrm{a}+\mathrm{b}=$ signo), sino que se deduce también de rasgos que el texto adquiere por su función comunicativa y de su relación, como entidad distinta, con un universo significado.

También Coşeriu (1997: 76) habla de una doble relación semiótica en el texto, al considerar que la primera relación semiótica la da el hecho de que «los signos lingüísticos que constituyen el texto significan y designan inicialmente algo que entendemos especialmente en calidad de conocedores de estos signos y de sus reglas de utilización». El segundo «plano semiótico» es «lo que en realidad se interpreta», considerando la designación y la significación, juntas, un nuevo signo, «con un contenido de grado superior» (Coșeriu, 1997: 75).

La condición privilegiada del texto literario de manifestar en mayor grado el principio de una organización global de la materia verbal, con el fin de reflejar el universo extraverbal (o una de sus partes), ha hecho que este tipo de texto sea tratado, antes que otros tipos textuales, como signo del (un fragmento del) mundo. Por consiguiente, el texto artístico es considerado, en su relación con el mundo, a veces como un producto influenciado, modelado por las leyes de la realidad extratextual, y a veces, por el contrario, como una fuerza capaz de imponer sus propias «imágenes» a la realidad. 
Por otra parte, por mucho que se haya puesto en tela de juicio últimamente el término de estructura, parece difícil que se pueda rechazar la idea de Lotman (1970), según la cual, en el arte, el contenido (el significado) es trasmitido por la estructura modeladora de la obra literaria en su integridad y así, el texto se vuelve signo y las entidades que componen el texto, las palabras que actúan en la lengua como signos independientes, se vuelven elementos del signo en la poesía (por extensión, en la literatura).

La idea del texto - signo artístico-, como un todo, puede encontrarse apoyada y sugerida, al mismo tiempo, por el concepto de dinámica semántica, puesto en circulación por Jan Mukarovskỳ (1974) . Este término es la expresión del proceso acumulativo del significado y caracteriza tanto al enunciado como a todos los conjuntos superiores a éste (apartado, párrafo, texto), a lo largo de su actualización. Gracias a un proceso de este tipo, teniendo como base «el gesto semántico»o «la intención semántica», la obra se organiza como unidad dinámica desde los elementos más simples hacia el contorno más general.

La instauración de la unidad semántica y formal de un poema se produce, según Riffaterre (1983: 15-35), al nivel de la signifiance, por medio de un proceso cuyo eje está situado sobre dos palancas, expansión y conversión. Mediante este proceso, las variaciones y la multiplicidad de las representaciones se integran en un principio unificador estructurante.

Las investigaciones más recientes sobre los textos otorgan la calidad de signo al texto, en general (no solamente al texto literario), tomando en cuenta la extensión de la globalidad como propiedad discursiva de cualquier tipo de texto, o independientemente de dicha propiedad.

Yendo más allá de las antiguas sugerencias del funcionalismo de Praga, van Dijk (1972 y 1977) postula el nivel de la macro-estructura como nivel «global de descripción semántica». Desde el punto de vista teórico, este nivel asegura, por medio de la categoría de argumento del discurso, la compresión de la información del texto (o de una secuencia textual) y la formulación de las condiciones inherentes a la coherencia global ( $v s$. lineal) de un discurso (Dijk, 1977).

En la misma perspectiva del funcionalismo de Praga y de la gramática del texto holandesa, se pueden mencionar otras referencias a la globalidad, entre las cuales vamos a recordar solamente dos. Ruqaiya Hassan, al definir el texto, afirma que «un $\mathbf{T}$ es un conjunto unitario dentro del cual opera simultáneamente una multitud de pro- 
cedimientos integradores» (Hassan, 1979: 370), mientras que Scinto relaciona la globalidad con la pareja tema-rema, como la que «mejor caracteriza el texto, a un nivel suficientemente global como para captar su organización esencial en el acto mismo de la comunicación» (Scinto, 1983: 75).

El problema del valor sígnico del texto es planteado de una manera totalmente diferente por Heydrich y Petöfi (1980). A la pregunta: ¿qué significa para un objeto ser texto? los dos autores contestan: «entre otras cosas, esto significa, sin duda, que el objeto tiene ciertas propiedades que permiten a otra categoría de objetos del mundo (como los hombres, por ejemplo), que poseen habilidades lingüísticas incontestables, reconocer una relación (semiótica) específica entre el objeto y el mundo». Resumiendo: «éstos pueden interpretar aquéllos como signos» o con más precisión: «Los objetos con propiedades características del texto, si se emplean como tales, tienen que ser interpretados como signos» (Heydrich y Petöfi, 1980: 19). Interpretamos esta ecuación de nuestros autores como una expresión de la convicción de que el valor de signo del texto, en general, se instituye por vía pragmática, precisamente por el uso textual de una medida verbal, idea apoyada también por Vasiliu (1990), que la argumenta a través de instrumentos lógico-formales. Pero, tanto en un caso como en el otro, el interés de los investigadores se orienta con predilección hacia el examen de ciertos aspectos o propiedades (algunos inherentes, otros extrínsecos) que hacen de una sucesión de unidades verbales de tipo oracional-fraseológico un texto (o una secuencia textual).

\section{LA AMBIVALENCiA SÍGNICA DEL TEXTO}

Por consiguiente, si incluimos el texto, en su calidad de categoría, en la esfera de los objetos semióticos, debemos reconocerle tanto el valor de conjunto sígnico verbal, como el de signo verbal complejo. Le atribuimos, de esta manera, al texto un estatuto semiótico ambivalente, diferente de lo que se podría entender de la formulación elegantemente oximorónica de Petöfi y Olivi (1989: 191): «A text [...] is a complex verbal sign (or a verbal sign-complex)», donde la relación disyuntiva entre los dos sintagmas definitorios conlleva a una interpretación equívoca: al conferirle a «or» un sentido exclusivo, una de 
las dos alternativas es eliminada, y al atribuirle un sentido identificador, posible también, se anula la distinción entre las expresiones, convirtiéndolas en equivalentes.

Mi hipótesis es que, desde el punto de vista semiótico, el texto se caracteriza por una ambivalencia constitutiva. Tener en cuenta esta ambivalencia semiótica del texto no significa admitir sólo una focalización sobre los procesos de naturaleza sintáctica, semántica y pragmática que implica la ejecución de un (o de cualquier) texto/ discurso; considero igualmente necesarios los acercamientos destinados a seguir el funcionamiento del texto (como entidad global) tanto en la red de las relaciones obligatorias del proceso comunicativo (donde se valida como objeto sígnico de cambio), como en la de un proceso de conocimiento en el cual y por el cual, el texto se instituye como signo.

Por eso, en la discusión siguiente, el texto se va a tratar como entidad eminamente verbal, $y$, al mismo tiempo, como parte de un proceso sígnico complejo y reflejo de éste. Algunas de las características esenciales de la textualidad (entendida como la calidad de un proceso verbal de cumplir ciertas condiciones del proceso semiótico) representan la expresión de unos fenómenos inmanentes, determinados por la constitución verbal del producto, mientras que otros son extrínsecos y se inscriben en la esfera de los fenómenos generativo-perceptivos. A través de las primeras, la textualidad verbal puede definir su propia «identidad», en sincronía con otras posibles textualidades (noverbales), y también a través de las mismas se asegura la relativa estabilidad estructural, en diacronía, de unos (sub-)tipos textuales. Los fenómenos generativo-perceptivos representan el lado creativo, aleatorio del proceso, y se responsabilizan tanto de la movilidad, en el tiempo y en el espacio, de la significación textual, como del debilitamiento, hasta la transformación o la sustitución, del esquema estructural o del molde constitutivo ${ }^{1}$.

Si la descripción de los aspectos constituyentes se inscribe con preponderancia dentro de la dimensión sintáctico-semántica de una interpretación semiótica, el examen de los aspectos generativo-perceptivos no se puede realizar más que desde la perspectiva pragmático-semántica.

1 Una discusión más amplia con respecto a la dinámica de los sistemas semióticos, en general, y del literario, en especial, encontramos en el estudio de Lotman (1976). 


\section{NIVELES TEÓRICOS EN LA INVESTIGACIÓN DEL TEXTO}

En algunos trabajos anteriores (Vlad, 1982a y 1982b) he establecido tres niveles, teóricamente separables, en el examen del signo complejo texto, niveles que he representado, según el criterio de su grado de generalidad (abstracción), de la manera siguiente:

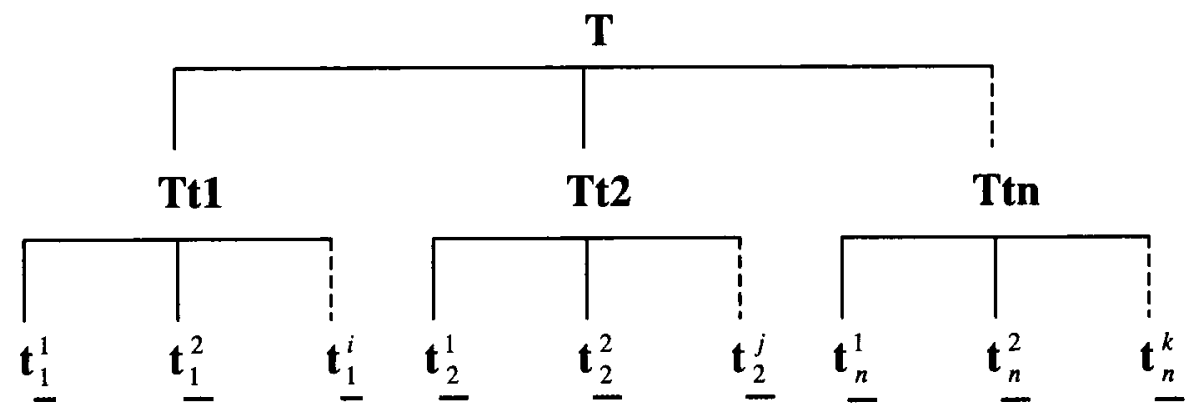

En esta alternativa he considerado a $\mathbf{T}$ como la expresión de la competencia textual (o comunicativa-verbal), que consiste en una regla de comunicatividad, en una regla de coherencia textual o macro-estructural y en una regla (o reglas) de orden secuencial de las unidades textuales manifiestas (Vlad, 1982a: 78-79 y 1982b: 315-316). T representa el más abstracto término del modelo.

El nivel t ha sido concebido como una imagen convencional de la percepción y de la descripción de cada texto-ocurrencia bajo su aspecto de producto verbal o «infratextual», como lo llama Lotman (1974: 80-92). Una descripción $t$ debe reflejar:

a) los dos sistemas que se relacionan (es decir, los protagonistas de la comunicación, por medio de sus principales atributos psico-, socioy etno-linguiísticos), el tiempo efectivo de la comunicación y su espacio concreto;

b) la estructura semántico-pragmática (referencial, modal e ilocucional) del texto-ocurrencia; 
c) su estructura micro y macro-sintáctica (locutoria e ilocutoria). Por $\mathbf{t}$ se ha simbolizado el nivel menos abstracto del modelo que, en algunos investigadores, se encontraría bajo el término de discurso.

El nivel Tt, del tipo textual, ha sido considerado la expresión de unas cuotas superiores que nuestro conocimiento puede alcanzar a lo largo del proceso de análisis-interpretación textual bajo la incidencia de la funcionalidad de los textos dentro de un sistema socio-cultural particular (Vlad,1982a: 87-88). En estas circunstancias, los dos sistemas interrelacionados (o papeles comunicativos) se consideran como valores (generales) relevantes o estatutos de unos grupos socio-culturales comprometidos en una interacción persistente, constante y reconocida; el tiempo de la comunicación comprime, por una convención cultural-histórica, una continuidad de momentos de una cronología histórica, y el lugar de la situación comunicativa adquiere el aspecto de un «espacio ritual». He definido la categoría Tt (Vlad, 1982a: 9192) como una representación de una estructura semántico-sintáctica (básica), dominada por una función socio-cultural constante a lo largo de toda la interacción comunicativa, cuando la interacción se desarrolla en una situación comunicativa, caracterizada por la constancia de los tres parámetros: papeles socio-culturales, intervalo «histórico» de tiempo y «espacio ritual».

El nivel Tt de la representación gradual que he propuesto ha sido concebido como un nivel de la síntesis semiótica, en la que se concentran conocimientos y normas con respecto a cómo y qué se puede comunicar por el habla, en situaciones comunicativas socializadas. Cada cultura articula su propia experiencia cognitiva, acumulada en el tiempo, tanto por medio de su propio idioma, como por otros sistemas, no-lingüísticos. El resultado de la intersección de estas dos categorías de códigos se manifiesta en diversas categorías de textos que pertenecen, a su vez, a unas ramas interesadas o bien en el conocimiento de la realidad (textos referentes a la vida cotidiana, o textos históricos, o científicos), o bien en el conocimiento de los contenidos míticos, religiosos o fantásticos, o bien en el conocimiento poético, o bien en la normalización de las relaciones sociales (es el caso de los textos jurídicos, administrativos o políticos).

Recordaríamos, de forma condensada, la solución que he preconizado, en primer lugar, para subrayar que es el resultado de una interpretación semiótica orientada preponderantemente hacia la competencia 
comunicativa de la esfera de los procesos textuales. En segundo lugar, para ver si el modelo sigue guardando algo de su relevancia en la situación de un cambio de perspectiva, es decir, cuando la investigación enfoca el proceso cognitivo en el que el texto (cultural o no) es asumido como signo.

\section{LA SEMIOSIS TEXTUAL}

El cuadro semiótico más adecuado para este tipo de investigación es, en mi opinión, el elaborado por Ch. S. Peirce. A pesar de ser una figura monumental de la filosofía, de la lógica y de la semiótica, desde fines del siglo pasado y comienzos del nuestro, representativa para el espacio americano, Ch. S. Peirce llega a la conciencia científica del continente europeo muy tarde, determinando, como en tantas otras ocasiones ante las grandes personalidades, actitudes divergentes, que van desde la reserva o la consternación hasta la adhesión filtrada o entusiasta. En cuanto a eso, la hipótesis epistemológica de François Peraldi (Langage, 1980, 58) me parece convincente: la obra semiótica de Peirce apareció «trop tôt», en comparación con la evolución de unos ámbitos conexos, mientras que el comienzo real de la semiótica de Peirce, como nueva ciencia, se ha vuelto posible sólo con los desarrollos de Saussure y post-Saussure de la linguiística, de la semántica y de la lógica.

Tal y como advierte Gérard Deledalle, el autor de unos importantes trabajos consagrados a la semiótica de Peirce, la teoría del signo, tal y como la concibe el lógico americano, no se puede tratar como una versión cualquiera, entre otras, fácil de relacionar para obtener una teoría completa y perfecta del signo. Todo lo contrario, observa Deledalle (Langage, 1980, 58) se tiene que saber que neologismos como representamen, intérprete, icono, rema y muchos otros más, no son equivalentes y, por consiguiente, tampoco son sustituibles por significante, significado, imagen o, respectivamente, concepto. Como término esencial, semiosis es el nombre del proceso de producción y funcionamiento sígnico, un proceso triádico en el cual están implicados el pensamiento, el signo y el mundo como entidades inseparables. Siguiendo los términos del cuadro semiótico de Peirce, trataré de poner de manifiesto algunas particularidades de la semiosis cuyo signo primordial es el texto. 
Me he decidido por la teoría semiótica del filósofo americano por unos cuantos motivos que voy a exponer a continuación:

(i) Un primer argumento (con posibles implicaciones epistemológicas) está vinculado con la esfera lógico-filosófica del pensamiento de Peirce. Como doctrina formal de los signos, la semiótica, por medio de la comunidad de sus investigadores, constituida por «inteligencias científicas» capaces de «observaciones abstractivas» y de rigurosos razonamientos, tiene conclusiones para ofrecer «con respecto a lo que sería verdadero sobre los signos en todos los casos» y le queda por descubrir «lo que tiene que haber y no sólo lo que hay en el mundo real» (C. P. 2: 227). Además, según Peirce «cualquier operación intelectual implica una tríada de símbolos» (C. P. 2: 300) y este tipo de signo «está ligado a su objeto según la idea que tiene la mente que utiliza el símbolo, idea sin la cual este tipo de relación no existiría» (C.P. 2: 299).

Si relacionamos la investigación textual con este cuadro general de pensamiento, entonces debemos aceptar que, al ser una actividad intelectual interesada en el análisis y la interpretación del texto verbal, en su reproducción y recepción, cualquier interpretación de texto se debe realizar desde la perspectiva de una relación triádica que «is genuine, that is its three members are bound together by it in a way that does not consist in any complexus of dyadic relations» (C.P. 2: 274).

(ii) En segundo lugar, digamos que la misma teoría nos proporciona los términos básicos de la relación triádica, a través de la conocida definición de Peirce, en la que semiosis significa «una acción o una influencia, que es o implica una cooperación de tres sujetos, es decir un signo, su objeto y su interpretante, sin poder reducir de ninguna manera esta influencia tri-relacional a una acción entre parejas» (C. P. 5: 484). Es adecuado precisar ahora que Peirce hace una distinción clara entre semiótica, por un lado, a la que considera «la doctrina de la naturaleza esencial y de las variedades fundamentales de las posibles semiosis» (C. P. 5: 459) o, según la formula de Eco (1992: 238), un «discurso teórico sobre la semiosis» y, por otro lado, semiosis, es decir el proceso o la acción triádica o tri-relacional. Según Eco (1992: 238), el proceso semiósico tiene lugar cuando: (i) un objeto o un estado del mundo (es decir, el objeto dinámico del modelo de Peirce) (ii) es representado por un representamen y (iii) cuando el significado (el 
objeto inmediato) de este representamen se puede traducir en un interpretante, es decir en otro signo. Aquí sólo encontramos otra manera de expresar el famoso enunciado de Peirce (C.P. 2: 274): «Un signo o representamen es un primero que mantiene con un segundo, llamado su objeto, una relación triádica tan auténtica, que ella puede determinar un tercio, llamado su interpretante, a mantener con su objeto la misma relación que mantiene el signo mismo con el mismo objeto».

(iii) En tercer lugar, para lo que vamos a emprender, considero útil una circunscripción inicial, tal vez banal, pero obligatoria, de una semiosis textual (como tipo o variedad de semiosis) que se convierte en posible, en un primer momento, a través de la especificación de los tres «sujetos» 2 .

De esta manera, el Representamen o el signo, el elemento primo (notado con R), es un (cualquier) texto (o secuencia textual o enunciado textual). El papel de R-TEXTO de mediar entre el objeto y el interpretante (representando al objeto y diciendo algo sobre el mismo para determinar una interpretación ${ }^{3}$ ), se realiza de una forma tanto más evidente como compleja. «El soporte» de la evidencia consiste en la naturaleza sígnica de las palabras-materia de la construcción del texto, mientras que la complejidad es la consecuencia de las variadas posibilidades de selección y combinación de los signos elementares-palabras (disponibles en el sistema de una lengua), cuando éstos son utilizados para formar unas expresiones derivadas de dimensiones variables. Por otra parte, la complejidad es también el efecto del conjunto de los factores implicados en el circuito comunicativo. Teniendo, por consiguiente, una función sígnica, R-Texto no es un signo, sino «el sistema abierto (s.a.-H.P.) de los signos productivos: en un sistema caracterizado por la totalidad, por su capacidad de transformación y por su dinamismo auto- regulador, todos los signos son co-signos» (Parret,

2 Partiendo de una plataforma parecida, Mariana Neţ (1995) estudia el ámbito de la actividad lexicográfica y propone un examen de los conceptos de sentido, referente y definición a través del cuadro de la semiótica de Peirce. El proyecto más general de la autora, referente al concepto del semiólogo americano, preconiza el esbozo progresivo «de la réconstruction de son système sémiotique (y compris le fonctionnement de ses catégories fondamentales), qui serait appliqué seulement ensuite aux divers domaines particuliers concrets de l'analyse de langue» (Neţ, 1992: 1313). Es precisamente lo que Mariana Neţ realiza en algunos de sus estudios $(1991,1992)$.

3 «... cada signo tiene, de hecho o virtualmente, lo que podemos llamar un precepto de explicación según el cual debe ser entendido, para decirlo así, como una especie de emanación de su objeto», afirma Peirce (C.P. 2: 230). 
1983:17), entendiendo por co-signo la obligación de relacionar cada signo con, por lo menos, otro.

El objeto en la semiosis textual (notado a continuación $O$ ), es $O$-EL MUNDO, porque aceptamos junto con Peirce (C.P. 2: 231) entender por Objeto «precisamente lo que se supone conocer ya para que el signo pueda aportarnos más información sobre el mismo», aceptando, también que cualquiera de los objetos del signo puede ser «una cosa individual conocida como existente, $o$ una cosa que se cree haber existido o que esperas que exista, o una colección de cosas así, o una cualidad o relación, o hechos conocidos [...]; o algo de una naturaleza general, deseado, pedido o encontrado invariablemente en ciertas circunstancias generales» (C.P. 2: 232). Es importante señalar que, dentro de la categoría de Objeto, Peirce recomienda que se haga una distinción entre El Objeto Mediado o Dinámico $(O d)$ y El Objeto No-mediado o Inmediato (Oi) del mismo signo. El primero es $\mathrm{El}$ Objeto de fuera del signo, que éste «debe indicar por una sugerencia; y esta sugerencia, o su contenido, es El Objeto No-mediado», es decir, el «del interior del signo» 4 . Por lo tanto, el acceso a $\mathrm{Od}$ (del exterior del signo) pasa por $O i$ (del interior del signo) que, sin embargo, según la definición del signo, es determinado por el primero.

Para la semiosis de tipo textual, la distinción entre $O d$ y $O i$ me parece más productiva de lo que pueda parecer a simple vista, y su valor aumenta, seguramente, cuando la discusión avanza hacia la problemática global del texto literario y, particularmente, hacia el problema de la relación entre realidad y ficcionalidad dentro de este tipo de texto. Pero en este momento, cuando el debate tiene como objetivo el texto en general, como categoría anterior y supra-ordenada a cualquier diversificación tipológica, la distinción entre $O i$ y $O d$ es relevante porque puede dar cuenta de la implicación recíproca en $R$-TEXTO tanto del objeto construido en y por el texto, como del objeto exterior al texto, perteneciente al mundo extra-textual/extra-verbal, cualquiera o de cualquier tipo fuera éste.

El Interpretante, en general y todavía sin diferenciar (transcrito a continuación por $I$ ), es «un signo equivalente o tal vez un signo más desarrollado» (Peirce, C.P. 2: 228) del signo primero ${ }^{5}$. Desde la pers-

\footnotetext{
${ }^{4}$ Las citas son de Lieb (1953).

5 Deledalle (1985: 33-34) afirma sobre el interpretante que es «el signo o la clase (el campo) de signo que nos permite atribuir el signo presentado al objeto al que re-presenta».
} 
pectiva de la semiosis textual, $I$ es cualquier «pensamiento» («imagen») equivalente, producido(a) en una inteligencia humana por un RTEXTO en relación con un O-MUNDO. En el caso de una «imagen» no-explicitada, «el interpretante es lo que el signo crea en su intérprete, determinando en él un sentimiento o una acción» (Oehler, 1985: 62), y cuando «la imagen» se vuelve explícita, ésta adquiere la forma de otros nuevos R-TEXTOS, en un circuito semiósico nuevo, en una serie teórica ilimitada (Peirce, C.P. 2: 303) donde «la conciencia inteligente» tiene que participar.

Para facilitar la comprensión del modelo semiósico preconizado por Peirce (nuestra principal referencia), voy a introducir a continuación una de las visualizaciones imaginadas, la de Deledalle (1985: 50-51), en la cual están incluidos todos los términos básicos del proceso, con sus principales categorías:

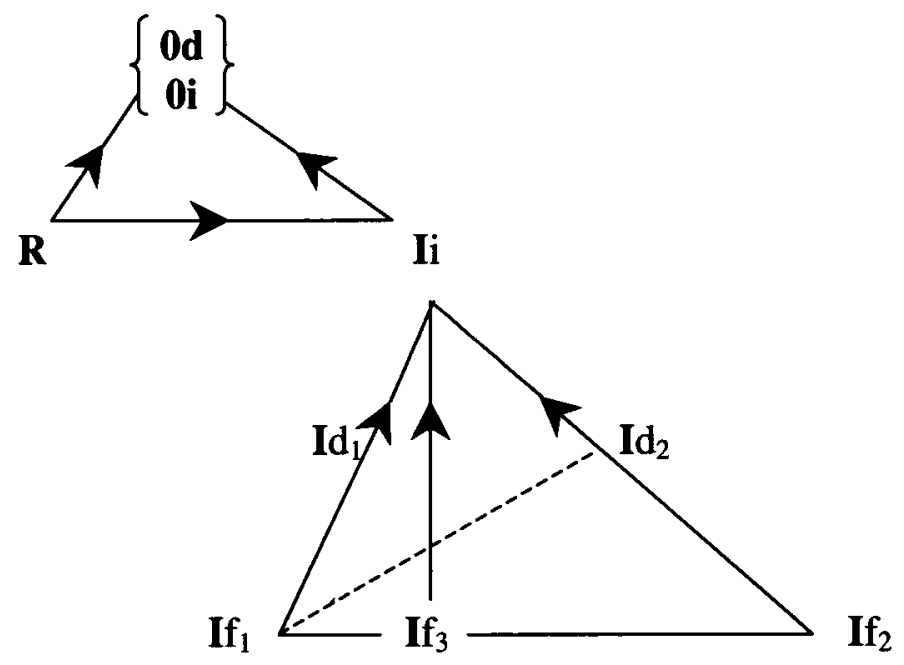

Donde: Od = objeto dinámico o «el mediado exterior al signo»

$\mathrm{Oi}=$ objeto inmediato o «el no-mediado del interior del signo»

$\mathrm{R}=$ representamen

$\mathrm{I}=$ interpretante (en general) «es todo lo que el signo transmite»

$\mathrm{Ii}=$ interpretante inmediato, «interpretante emocional»

Id = interpretante dinámico, «interpretante energético»

If $=$ interpretante final, «interpretante lógico» 6 .

${ }^{6}$ Estas últimas caracterizaciones de los tres interpretantes, li, Id e If se encuentran en Peirce (1955: 277). 


\section{EL INTERPRETANTE INMEDIATO Y LA TEXTUALIDAD}

El intento de captar el proceso de percepción «gradual» del texto como signo verbal complejo va a empezar por un examen más detallado del Interpretante inmediato ( $I$ i) en la semiosis de tipo textual, relacionando el modelo de Peirce y unas contribuciones inspiradas por éste (Deledalle, 1985; Oehler, 1985; Eco, 1992; Neț, 1991 y 1995) con la solución ya presentada esquemáticamente ( $c f$. supra, 2.3.)

Como se ha visto ya, la primera «especie» de Interpretante es el inmediato, $\mathrm{I}$, conformado, como tantas otras categorías de la concepción semiótica de Peirce, por unas cuantas idas y vueltas sucesivas en la obra del lógico. Así, $I i$ «está implicado en el hecho de que cada Signo debe tener su propia interpretabilidad particular, antes de llegar a tener cualquier intérprete», siendo «una abstracción que consta de una posibilidad». Este «interpretante emocional»-como lo llama Peirce- cubriría una zona de significación situada entre la simple «impresión de reconocimiento» (feeling of recognition) del signo y la impresión (la disposición) producida por el signo a través de su «primer efecto específico de significación» ${ }^{7}$, motivo por el cual, en Deledalle (1985: 34) lo encontramos también bajo el nombre de interpretante «afectivo» o «sugestivo» $y$ «perceptivo».

En nuestra opinión, $I i$ de una semiosis de tipo textual corresponde a la capacidad del intérprete de percibir la naturaleza textual de un signo-verbal-complejo, es decir, de realizar «las impresiones» o de percibir las sugerencias de comunicatividad, de referencialidad y de secuencialidad. La interpretabilidad ulterior del texto como tipo de signo depende del efecto conjugado de estas virtualidades suyas, por medio de las cuales, por un esfuerzo amplificado, se puede obtener un conocimiento más profundo del signo. Ii de la semiosis de tipo textual es, para nosotros, el equivalente de la textualidad $(=\mathbf{T})$.

Sobre la comunicatividad se puede decir, con perfecta justificación, que es un rasgo implicado en el funcionamiento general-sígnico, por lo tanto que pertenece a la naturaleza de cada objeto, cuando éste cobra valor de signo en una semiosis. La idea es congruente con algunas afirmaciones de Peirce, de las que citamos: «[...] los signos necesitan dos

7 «The first proper significate effect of a sign is a feeling produced by it» (Peirce, 1955: 277). 
casi-pensamientos, un emisor y un casi-intérprete y, aunque los dos sean un solo pensamiento, en el signo esta distinción, sin embargo, se tiene que hacer [...] Por lo tanto, es una necesidad de la lógica que cualquier evolución del pensamiento sea dialógica» (C.P. 5: 551), ya que «Cualquier pensamiento tiene una forma dialógica» (C.P. 6: 338).

Casi espontáneamente, por una asociación totalmente natural, recordamos las ideas, perfectamente consonantes, expresadas por Bajtín en los años 1940 sobre la comunicación verbal: «La orientación dialógica del discurso es, por supuesto, un fenómeno propio de cualquier discurso» o «el discurso concibe su objeto de manera dialógica» (1982: 134).

Oehler (1985) también constata que hacia el final de su actividad, Peirce llega a concebir el pensamiento como un proceso comunicacional, desarrollado bajo la forma de un diálogo, mientras que Mariana Neț (1992), observando la polisemia del término pensée interprétante (interpretative mind), propone una posible clarificación de su ambigüedad a través de la identificación de dos actantes distintos: «l'un pour la sémiose de gauche à droite et l'autre pour la sémiose de droite à gauche ("à rebours")", actantes comprometidos en un proceso dialógico.

Entendemos por referencialidad (o contextualidad), como virtualidad del signo-texto, su capacidad de producir en el intérprete, a nivel de Interpretante inmediato, la disponibilidad para indicar al $O d$ «exterior al signo» por medio de la sugerencia contenida en el $O i$ del signo, para que éste último, muy poco después, pueda ser identificado, delimitado y actualizado, al nivel de los demás interpretantes.

Voy a apelar de nuevo a Peirce y les recuerdo que según el tercer criterio principal de clasificación de los signos, «según su interpretante lo represente como un signo de posibilidad, como un signo de hecho o como un signo de razón» (C.P. 2.243), existen los tipos llamados rema, dici-signo y argumento. En el sentido atribuido aquí a la referenciali$\mathrm{dad}$, como una de las virtualidades que constituyen «el campo» del Ii, la considero signo de tipo remático, porque funciona igual que éste, es decir, «para su interpretante es un signo de posibilidad cualitativa, en otras palabras se le entiende como representante de un objeto, de un tipo o de otro. Un rema puede proporcionar una información cualquiera, pero no se le interpreta como proveedor de esta información» (C. P. 2: 250). De hecho, esta caracterización como signo remático puede ser atribuida también a las demás disponibilidades del campo de acción del $I i$. 
Sin embargo, hay que apuntar que se ha sustituido «la regla de coherencia textual o macro-estructural» del modelo estratificado de la recepción textual por la referencialidad. He considerado necesaria esta modificación por las siguientes razones:

(i) por la convicción de que la referencialidad representa una condición esencial del texto, del mismo valor que la comunicatividad y la sucesividad;

(ii) porque el termino de coherencia, tal y como fue definido (Vlad, 2000: 172- 180), es tratado como equivalente de la textualidad, por tanto como un círculo de los tres principios;

(iii) desde la perspectiva del sentido textual, la coherencia conceptualiza la totalidad de las relaciones de las que depende la interpretación de éste, en cada acto textual-discursivo en parte.

El tercer componente, la secuencialidad o sucesividad, deriva de la naturaleza verbal del signo-texto, de la «linearidad», material de su expresión. «La sensación» de sucesividad determinada por la temporalidad intrínseca del habla y de la sonoridad, como materialidad propia del lenguaje y adecuada a la naturaleza del habla (Coșeriu, 1988: 211-212) - independientemente de la forma de pronunciar, oral o gráfica-, se activa en la primera etapa del proceso sígnico textual, siendo preeminente a cualquier comprensión del contenido comunicado en y por el acto discursivo.

Los tres componentes del $I i=T$ representan la condición inicial, «el resorte» que provoca la semiosis de tipo textual. Por la aparición en Ii de estas tres características latentes, en igual medida disponibilidades, se realiza la función esencial de un signo, que consiste en «transformar en eficientes relaciones ineficientes», es decir, en «establecer una costumbre o una regla general gracias a la cual estas relaciones actuarán cuando sea debido» (C. P. 8: 332).

Las disponibilidades de comunicatividad, referencialidad y sucesividad se caracterizan no por una participación independiente o «puntual» en el proceso de la semiosis, sino, todo lo contrario, por acción simultánea, gracias a un sincretismo sígnico y funcional.

Una vez comprobadas, las constataciones arriba mencionadas llevan a concluir que, a través de los tres componentes, el interpretante inme- 
diato se convierte en el principio básico del funcionamiento textual, que coincide con la significación textual o, más fácil, con la textualidad.

Este modo de entender la textualidad sólo coincide parcialmente con otras opiniones expresadas anteriormente. Para Beaugrande y Dressler (1981: 3- 11; Beaugrande, 1984: 37- 39), la textualidad consta de siete estándares, como «principios constitutivos» a través de los cuales se define y se crea una forma de comportamiento identificable como comunicación textual. Los estándares son: la cohesión, la coherencia, la intencionalidad, la informatividad, la aceptabilidad, la situacionalidad y la intertextualidad. Los autores especifican que una secuencia verbal que no satisface todos estos estándares, no puede sèr considerada texto, sino no-texto. Si se compara el punto de vista de Beaugrande y Dressler con el preconizado anteriormente, se puede constatar un posible acercamiento, en la medida en que algunos de los siete parámetros pueden ser asociados a un componente u otro del Ii. Se trata de intencionalidad, aceptabilidad y situacionalidad, por un lado, presentes en la esfera de la comunicatividad, y, por otro, de coherencia e intertextualidad, interfiriendo en la esfera de la referencialidad y, por fin, de cohesión e informatividad, relacionadas con la esfera de la sucesividad.

Una visión aparentemente diferente se encuentra, por ejemplo, en Petöfi y Olivi (1989: 191), para quienes la textualidad «no es una propiedad inherente de los objetos verbales», porque «un productor o un receptor considera un objeto verbal como si fuera texto (solamente) si cree que este objeto verbal es un texto unitario completo, que satisface una intención comunicativa real o asumida, en una situación comunicativa real $o$ asumida».

Me gustaría hacer unas cuantas observaciones a estas aserciones:

(i) La textualidad no puede ser una propiedad inherente de los objetos verbales, sino solamente de los objetos textuales, los primeros teniendo como característica la textualidad; estas dos propiedades, la verbalidad y la textualidad, pertenecen a unas órdenes distintas $o$, dicho de otra manera, caracterizan dos sistemas sígnicos (dos componentes del lenguaje) distintos en cuanto a la manera de funcionar de los signos, aunque estos últimos sean parcialmente coincidentes. La idea fue expresada por Coșeriu (1993) y luego re-formulada, desde otra perspectiva, por Stati (1991: 131), quien, hablando de la naturaleza 
real de las relaciones entre las gramáticas (frásticas) tradicionales y las transfrásticas, considera que este aspecto debe ser re-examinado sin prejuicios, dado que «el problema más difícil no es el de encontrar y aplicar al texto analizado una de las relaciones sintácticas tradicionales, sino la de la auténtica naturaleza de estas relaciones que podrían coincidir con la subordinación y la coordinación gramatical». Para apoyar esta afirmación Stati menciona, siguiendo una lista proporcionada por van Dijk, una serie de posibles relaciones entre las frases de un texto, como por ejemplo: preparación, explicación, especificación, contraste, comparación, ejemplo... todas completamente ajenas a las «etiquetas tradicionales». Por supuesto, el aspecto arriba mencionado es solamente uno de los que se deben profundizar y reevaluar a continuación.

(ii) Aunque se reconozca que la calidad de texto de un objeto verbal depende de las condiciones del acto de comunicación, ello no significa excluir el texto de entre los objetos de naturaleza verbal, sino solamente afirmar que, entre estos objetos, el texto se particulariza funcional y semióticamente. El estatuto de signo del texto no puede ser definido, ni descrito, en los términos del modelo binario de Saussure o de otro de este tipo. Por eso, la consecuencia inmediata en el plano de la teoría del texto ha sido reconocer su estatuto de categoría pragmáti$\mathrm{ca}$, actitud general en base a la cual, sin embargo, algunos lo han situado exclusivamente dentro de la esfera de la pragmática, y otros en la esfera del circuito semiótico completo, incluyendo también las otras dos dimensiones semióticas ${ }^{8}$.

De este breve examen sobre la textualidad no puede faltar la contribución de E. Vasiliu (1990), que le consagra un libro entero, ya que Introducción a la teoría del texto es el volumen de una sola idea: definir la textualidad con bases e instrumentos formales dentro del marco conceptual de la semiótica verbal.

Cuando «la propiedad de una cadena de elementos -oracionesde ser texto" (Vasiliu, 1990: 21) se somete a un examen serio, desde la perspectiva de la más fuerte y restrictiva sintaxis generativo-transfor-

\footnotetext{
${ }^{8}$ La primera de las hipótesis básicas de una pragmática textual preconizada por J.M. Adam (1990: 107) es que «cada componente humano en la esfera de lo simbólico y, en particular, de lo simbólico linguiístico, tiene el carácter de la texticidad» (es decir, de la textualidad).
} 
macional (la versión de 1957 de N. Chomsky), al concepto de textualidad no se le puede atribuir, en la opinión del autor, más que el sentido de «texto bien-formado», en base a la analogía con el ámbito de la oración y de la frase. En esta alternativa (que sería la única correcta), sin embargo, se comprueba que una definición rigurosamente sintáctica no es posible, ya que «no se puede construir una sintaxis sobre la base (una base estrictamente formal) de discernir entre textos y no-textos. Por consiguiente, no se puede dar una definición sintáctica de la textualidad, tal y como podemos dar una definición estrictamente sintáctica de la noción de oración (frase) bien formada» (Vasiliu, 1990).

El mayor espacio del libro lo ocupa el debate sobre la textualidad desde la perspectiva de su posible pertenencia a la esfera de los aspectos semánticos y de su definición dentro de esta misma esfera. La primera precaución, completamente justificada, que toma el autor es la presentación precisa del cuadro teórico asumido en la discusión sobre la estructura semántica del texto. En este cuadro encontramos, con prioridad, el modelo de la semántica lógica —una semántica referencial con dos componentes, extensional e intensional, siguiendo la línea desarrollada por Frege, Tarski y Carnap - al lado de algunas sugerencias, compatibles y útiles, desde la semántica oracional/frástica de orientación generativista.

Siguiendo un razonamiento claro, E. Vasiliu constata que sólo la relación con la estructura semántica de la oración nos permite decidir «si la estructura semántica del texto (cuyos constituyentes inmediatos son las oraciones) puede ser determinada con referencia a la estructura semántica de sus constituyentes inmediatos, el grupo-sujeto y el grupo-predicado, y en qué medida» (1990: 52).

Partiendo de la premisa de que «la semántica tiene en cuenta la relación entre signos y objetos, y nada más» (s.n.-C.V.) y que «el sentido de las entidades sintácticas de rango inferior depende estricta y exclusivamente del sentido de las entidades constituyentes de rango inferior» (Vasiliu, 1990), conforme al principio de «composicionalidad» de Frege, el autor de la Introducción a la teoría del texto somete a un análisis crítico, una por una, a las más significativas contribuciones al ámbito de la teoría del texto, especialmente de la semántica textual. Así, se comentan los siguientes problemas: los conectores textuales, la coherencia y la co-referencia, la estructura profunda del texto y la coherencia, la modelización matemática de la coherencia, el resumir y la semántica procesual (los dos últimos relacionados con la coherencia). 
Respetando el cuadro estricto de la concepción semántica adoptada desde el principio, este análisis, efectuado con pertinencia científica, conlleva a las siguientes conclusiones principales:

(i) las teorías discutidas «no explican en el fondo 'la coherencia' en términos semánticos propiamente dichos»;

(ii) «no ofrecen una base para formular reglas, según las cuales, para cualquier sucesión de oraciones se pueda decidir si es o no coherente, por tanto si está o no está en el texto»; y, por fin,

(iii) «tenemos que aceptar la idea de que, por lo menos al nivel actual de las investigaciones, la textualidad no puede ser definida en términos semánticos» (s.n. C.V.) (Vasiliu, 1990: 102-103).

La única vía fértil y cercana a la definición rigurosa y matizada de la textualidad resulta ser, para Vasiliu, la pragmática.

De esta manera, la textualidad, cuya naturaleza pragmática fue relevada y aceptada por otros especialistas también, cobra ahora un contenido completamente nuevo: «la conformidad entre el modo en que las oraciones se suceden y la expectación en cuanto a la manera de sucesión de las oraciones» (Vasiliu, 1990: 110). El aparato formal construido por el autor es destinado a expresar con exactitud y rigor las siguientes ideas (Vasiliu, 1990: 115-117):

a) «los textos son filas de oraciones yuxtapuestas»;

b) las filas de oraciones se obtienen a lo largo de «una actividad de construcción» por un «proceso adjuntivo a la derecha» (PAD);

c) «una fila de oraciones se construye paso a paso»;

d) «los procesos adjuntivos a la derecha "tienen" cierto grado de expectabilidad, en relación con la situación de comunicación» (s.n. C. V.), grado que puede cobrar diferentes valores, situados entre cero (disconformidad absoluta en relación con la expectación) y uno (conformidad absoluta con la expectación);

e) en cuanto a la sucesión de las oraciones existe una tolerancia variable «dependiendo de ciertos factores, como serían por ejemplo, el estilo funcional utilizado por los interlocutores, su experiencia linguística, la situación de comunicación, etc.»; 
f) al grado de tolerancia se le debe asociar el concepto de «permiso», en el que se refleja «la pluralidad de normas que gobierna el comportamiento lingüístico de los hablantes de cierto idioma»;

g) la noción de «coherencia» puede definirse en términos de «expectación»;

h) «la textualidad puede ser definida como coherencia».

El resultado de la elaboración y de la aplicación del aparato formal es espectacular, en la medida en que por lo menos dos constataciones fundamentales se validan de esta manera. Se demuestra de este modo que «un texto no es más que lo que se nos presenta y / o aceptado como texto y, por consiguiente, "la textualidad" no es una propiedad inmanente de una combinación (configuración) de signos (hemos discutido las situaciones en las que los signos que "se combinan" son oraciones y /o frases), sino una manera de presentación y la aceptación de una configuración así» (Vasiliu, 1990: 145). También, gracias a la flexibilidad del aparato formal (que apela a una lógica pentavalente), se pone de manifiesto el carácter gradual de la textualidad (y de la coherencia) en relación con «los sistemas de normas que gobiernan el uso lingüístico de una colectividad» (Vasiliu, 1990: 137).

Más allá de importantes diferencias en el plano teórico, esta última idea aparece también en trabajos recientes consagrados a la teoría de la conversación, lo que me parece sintomático para el desarrollo ulterior de la teoría del lenguaje. De esta manera, Catherine Kerbrat Orrechioni (1990: 204) observa: «la cohérence dialogale est un phénomène graduel» (s.n-C.V.).

Pero, frente a la observación de E. Vasiliu (1990: 24): «es evidente que, de acuerdo con nuestra intención, una sola frase puede constituir, por lo menos en ciertas circunstancias (s.n. C.V.), un texto (al igual que, en ciertas circunstancias, una oración también puede constituir un texto)», debemos preguntarnos no sólo cuáles serían esas «circunstancias» particulares, sino, sobre todo, que otra cosa más que la textualidad descrita por el autor, pero ausente en semejantes situaciones, es o se convierte en el soporte de la calidad del texto.

Volviendo insistentemente a la idea de la coherencia como hecho «de naturaleza pragmática», E. Vasiliu revela, cada vez, que, dentro de ella, la relación de los hablantes se establece «de manera directa con el sentido (s.a.-E. V.) de los signos» (Vasiliu, 1990: 67; 126). Veo en esta afirmación un argumento a favor de la opinión ya expresada (Vlad, 
1982 a: 77; 1994: 28 y 63, nota 9) en cuanto a la incapacidad de la tripartición de Morisse de dar cuenta de la totalidad de las posibilidades de observación y evaluación de las relaciones entre las entidades implicadas en el acto semiótico, ya que una relación sentido-utilizador no está estipulada.

Si el resultado al que llegamos con respecto a la textualidad, identificada con el interpretante inmediato de la semiosis de tipo textual, tal y como lo hemos concebido, es correcto, entonces debemos admitir también la idea que no se puede concebir la esencia textual de manera unilateral, exclusivamente pragmática, es decir, dependiente sólo de la intervención o la participación de hecho de un agente-utilizador de signos textuales. Por muy importantes que sean los aspectos de este tipo, ellos solos no son suficientes para determinar la existencia del signotexto o del texto como signo global, porque, para serlo, debería «prever» tanto su propia relación con el objeto como la del interpretante con el objeto, un signo siendo «un objeto en relación con su objeto, por un lado, y con un interpretante, por otro lado, de tal manera que ponga al interpretante en una relación con este objeto correspondiente a su propia relación con el objeto» (C. P. 8: 332).

Y, refiriéndonos otra vez a Peirce, voy a citar un pasaje cuyo contenido, más allá de su aparente banalidad, me parece en consonancia con el sentido que hemos atribuido a la textualidad $=I i$ (con sus tres componentes: la comunicatividad, la referencialidad, la sucesividad): «Resulta sin embargo de nuestra propia existencia (que está comprobada por la ocurrencia de la ignorancia y del error) que todo lo que está presente dentro de nosotros es una manifestación fenomenal de nosotros mismos. Lo que no le impide tampoco ser un fenómeno de algo de nuestro exterior tal y como un arco-iris es, al mismo tiempo, tanto manifestación del sol como de la lluvia» (C.P. 5: 283).

\section{Id e If EN LA SEMIOSIS DE TIPO TEXTUAL O RECEPCIÓN E INTERPRETACIÓN TEXTUAL}

Puesto en marcha por el interpretante inmediato, el proceso interpretativo se produce de manera efectiva y se profundiza progresivamente gracias al interpretante dinámico y al interpretante final. 
$I d^{9}$ tiene lugar «cuando un signo produce un efecto significativo particular, suplementario», y en las condiciones en que semejante efecto ulterior implica, a menudo, «un esfuerzo mental». El contenido de este «interpretante energético» es dado por todo aquello que, a través de la experiencia particular, se actualiza a lo largo de la interpretación y se constituye en un «acontecimiento actual único».

En función de: (i) la naturaleza del objeto (objeto inmediato vs. objeto dinámico), (ii) la naturaleza de los conocimientos puestos en juego por el intérprete (conocimiento por experiencia personal $v s$ conocimiento por experiencia «colateral»), (iii) la amplitud del contexto en el cual se realiza este nuevo esfuerzo cognitivo (experiencia personal limitada $v s$. contexto social-histórico) y (iv) el tipo de inferencia (abductiva $v s$. inductiva), Peirce distingue entre $I d l$ e $I d 2$.

A estos criterios de diferenciación de los dos interpretantes dinámicos se les añade también la posibilidad de que $I d$, en calidad de «interpretante factual», entre en relación, o bien con el objeto inmediato del signo (un ens rationis, una idea, «una representación»Oehler, 1985: 65), o bien con su objeto dinámico, «real», «del exterior del signo». Según la fórmula de Deledalle (1985: 50), «Idl es una lectura en el contexto actual del conocimiento del intérprete, lectura realizada abductivamente» y sin apelar a «una experiencia colateral», e «Id 2 es una lectura en el contexto social (exterior) o histórico (anterior) $o$ en los dos contextos», «una lectura realizada inductivamente».

En cuanto al interpretante final, If o «logical interpretant», éste representaría el objetivo mayor de cualquier intento suficientemente serio para llevar a resultados (más) generales, más allá del conocimiento «factual» del objeto, obtenido por experiencia personal, singular, dada por Id.

If tiene, a su vez, tres aspectos: If 1 , If 2 e If 3 , como tantas otras posibles vías por las cuales evoluciona la experiencia de conocimiento del signo, amplificándose gracias a la activación de unos tipos diferentes de razonamiento como: abductivo por inferencias hipotéticas (en IfI), inductivo (en If2) y deductivo (en If3). Frente a $I d l$ e $I d 2$, los primeros dos interpretantes finales representan una «extrapolación», como «costumbre general», no-controlable científicamente, en el primer

${ }^{9}$ «Id is that which is experienced in each act of interpretation and is different from that of any other» (Peirce, C.P. 5: 474). 
caso, y como «habitus» o «costumbre no-especializada» (Deledalle, 1985: 50), en el segundo.

Hemos mencionado estas ideas básicas de Peirce para aclarar la manera en la que el proceso semiósico de tipo textual se particulariza. Primero, si intentamos proyectar «los niveles perceptivos» del modelo estratificado de comprensión del texto (Vlad, 1982a y 1982b; cf. supra) en el sistema de los interpretantes ${ }^{10}$ de Peirce, vamos a observar que a los dos niveles, $T t$ y $t$ (que han quedado después de identificar $T$ con $I i$ ), no les corresponden exacta y totalmente los otros dos interpretantes, If e Id respectivamente. La relación es otra, dada, en primer lugar, la separación entre $I d I$ e $I d 2$ y la separación entre IfI, If2 e If3. En estas condiciones, tanto $t$ como $T t$ se van a encontrar con ciertos «componentes» suyos, tanto a nivel de $I d$ como a nivel de If. En otras palabras, tanto la experiencia estrictamente semántica (la actualización de las relaciones de significado verbal intratextual), como la tipológica (la actualización de las relaciones de sentido intertextual, intensamente cultural) se van a encontrar a nivel de $I d$ y también a nivel de $I f$.

Entonces, $I d l$ correspondería a $t$, representando una interpretación factual del objeto inmediato-textual dentro de los límites de las posibilidades de conocimiento de cada individuo y de sus capacidades de relacionar la experiencia personal «de vida» con el conocimiento verbal, a través de la competencia comunicativa-textual. La realización de este tipo de conocimiento va a determinar la actualización del sentido literal del texto, un sentido reducido a las posibilidades «inmediatas» del interpretante teniendo como resultado «une lecture de l'immanence du texte» (Neț, 1991: 38) o, en términos de Eco (1992: 36), el primer peldaño de la interpretación semántica o semiósica por la que el destinatario (o «el lector-modelo ingenuo») «llena de sentido» la parte manifiesta de un texto, en su orden lineal de desarrollo.

Cuando en el proceso semiósico a nivel de Id intervienen también elementos referentes al objeto dinámico, al contexto social del signo y al histórico, gracias a una «experiencia colateral» que parte de unos procesos de pensamiento de tipo inductivo, Id2 se esboza como «le résultat d'une lecture intertextuelle du texte» (Neț, 1991: 38). Esta

${ }^{10}$ Comentarios y puntos de vista, en general convergentes, con respecto a las posibilidades de entender la significación de todos los siete interpretantes del modelo semiósico de Peirce se pueden encontrar también en Deledalle (1985: 49, 51), Oehler (1985: 62-63), Eco (1985: 35-5; 1992: 238-241), Neț (1991). 
afirmación nos hace afirmar que se debe admitir la existencia de, al menos, unos «gérmenes» de tipología textual, como una mínima experiencia en el horizonte de conocimiento de cada individuo perteneciente a una sociedad avanzada culturalmente (Vlad, 1982 a: 84), cualquiera que fuera ese nivel cultural, y que «la raíz» de esta experiencia tipológica mínima se halla en $I d 2$. Por eso, $T t$ de nuestro modelo estratificado no se va a encontrar completamente a nivel de If, sino también a nivel de $I d 2$, precisamente por este aspecto mínimo (y general) de la experiencia tipológica textual que acabamos de mencionar. La constatación parece confirmarse también a partir del análisis semiótico realizado por Mariana Neț (1991) sobre el texto folclórico, visto desde la perspectiva de su percepción como símbolo cultural, resultado de una decodificación ingenua, que se situaría en la esfera de $I f I$, pero también del análisis del texto artístico cuando «l'application d'une grille artistique au symbole culturel mène le récepteur à la découverte de l'interprétant dynamique Id2» (Net,, 1991: 41).

Este aspecto, aparentemente paradójico, remarcado por Neț (1986: 131, 1991: 41), según el cual el interpretante final (If1 o If2) se constituye en un contexto exterior o anterior necesario para el conocimiento del interpretante dinámico Id2 (no solamente en la semiosis textual-artística, sino también en la lexicológica), no es ajeno tampoco, como hemos visto, a la semiosis de tipo textual, donde lo hemos relacionado con la «base natural» (por experiencia directa) del conocimiento tipológico, localizado en Id 2 y diferente del conocimiento tipológico adquirido a través del acto cultural de la formación.

En cuanto al nivel del interpretante final (Ifl, If 2 e If 3 ), hay que hacer unas cuantas observaciones:

(i) Una lectura textual realizada preponderantemente por el lado $\mathrm{I} i$ Id1-IfI (del triángulo esbozado por Deledalle) lleva a la decodificación del texto, es decir, a la comprensión literal de su contenido, por una actuación preponderantemente lineal, limitada en gran medida a la parte explícita del texto.

(ii) Una lectura textual, realizada preponderantemente por el lado Ii-Id2-If2, tiene como resultado la interpretación del texto, un proceso en el que la parte implícita es más intensamente explorada por un esfuerzo globalizador, dirigido por «costumbres controladas» por los 
diferentes códigos (semióticos), específicos de cada tipo textual. Refiriéndose a esta cuestión, Eco (1992: 36) formula la diferencia entre los dos aspectos arriba mencionados, en los siguientes términos: «La interpretación semántica o semiósica es el resultado del proceso por el cual el destinatario, en presencia de la manifestación lineal del texto, la llena de sentido. La interpretación critica o semiótica, en cambio, intenta explicar gracias a qué razones estructurales el texto puede producir estas interpretaciones semánticas (u otras, alternativas)».

(iii) El estatuto de If3 es de alguna manera diferente, por el hecho de que a este interpretante se puede llegar o bien por exploración, partiendo de If 1 , o bien por deducción, partiendo de If 2 , o bien por una relación directa con $I i$, haciendo abstracción de la etapa $I d$. En todas estas situaciones, If 3 es un interpretante sistemático, formal, independiente del contexto y, como todos los sistemas formales, es deductivo. Como muestras elocuentes de una interpretación de tipo If3, mencionaría dos libros: Sémantique structurale de A.J. Greimas (1996) e Introducere în teoria textului de Emanuel Vasiliu (1990): el primero, representando una posible interpretación-síntesis de lo semántico-verbal de la esfera de la langue, como interpretante inmediato del campo de significaciones de una lengua; y el segundo, ofreciendo uno de los modelos lógico-formales de la textualidad, como interpretante inmediato del ámbito textual.

Hasta aquí, toda la discusión no ha hecho más que argumentar a favor de la fecundidad de la noción de interpretante de la que Eco (1980) decía que «muestra cómo los procesos semióticos, a través de unos desplazamientos continuos, que envían un signo a otros signos o a otras categorías de signos, circunscriben significaciones o contenidos (en una palabra, aquellas "unidades" a las que la cultura ha individualizado en su proceso de hacer pertinente el contenido) de manera asimptótica, sin llegar nunca a "tocar" directamente, sino haciendo asequibles los hechos a través de otras unidades culturales».

Para el ámbito de lo textual, de los actos comunicativo-verbales, la noción de interpretante, como se ha visto, es extremadamente fértil; aquí, en el proceso semiósico ternario, al lado del signo y de su objeto, el interpretante, con sus peldaños y sus especies, es «el espejo mágico», simultáneamente convergente y divergente, en el que, por una alquimia particular, se produce el sentido textual proteico, en series teóricamente abiertas, infinitas. 


\section{Referencias bibliográficas}

ADAM, J. M. (1990). Eléments de linguistique textuelle. Théorie et pratique de l'analyse textuelle. Liège: Mardaga.

ASHER, N. (1996). «L'interface pragmatique-sémantique et l'interprétation du discours». Langages 123, 59-74.

AUCHLIN, A. y FERRARI, A. (1994). «Structuration prosodique, syntaxe, discours, évidences et problèmes». Cahiers de Linguistique Française 15, 28-41.

Bajtin, M. (1982). Probleme de literatură și estetică (traducere în limba română). București: Univers.

BARTHES, R. (1994). Plăcerea textului (traducere în limba română de M. Papahagi). Cluj: Echinox.

Beaugrande, Robert de (1984). «Text Production. Toward a Science of Composition». Advances in Discourse Processes, vol. II, Ablex Publishing Corporation.

Beaugrande, R. de y Dressler W. (1981). Introduction to Text Linguistics. London and New York: Longman Linguistics Library.

Chomsky, N. (1957). Syntactic Structures. The Hague: Mouton.

COŞERIU, E. (1988). «Tempo e linguaggio». En Undici conferenze sul tempo, E. di Angelis (ed.). Pisa.

- (1993). «Lingvistica: starea ei actuală». Revistă de lingvistică și știință literară 1 (145), 14-28.

COSERIU, E. (1997). Linguistica del testo. Introduzione a una ermeneutica del senso. Edizione italiana a cura di Donatella di Cesare. Roma: La Nuova Italiana Scientifica.

Deledalle, G. (1985). Teoria și practica semnului (trad. în limba română), S. Marcus (ed.). București.

DiJk, TEun A. VAN (1972). Some Aspects of Text Grammars. A Study in Theoretical Linguistics and Poetics. The Hague: Mouton.

- (1977). Text and Context. Explorations in the Semantics and Pragmatics of Discourse. London: Longman Group Ltd.

Eco, U. (1980). «Significato». En Enciclopedia, III, 859. Torino: Einaudi.

- (1985). Lector in fabula. Le rôle du lecteur. Paris: Grasset.

- (1992). Les limites de l'interprétation. Paris: Grasset.

Hasan, R. (1979). «On the Notion of Text». En Text vs. Sentence. Basic Questions in Text Linguistics, S.J. Petöfi (ed.), part 2. Hamburg: Buske.

HeYdrich, W. y PetöFi, J.S. (1980). «Pragmatic Considerations within a Text-

Theoretical Framework». En Some Aspects of Formal Foundations in Text Semantics, Eikmayer, Heidrich, Petöfi (eds.). Universität Bielefeld.

Greimas, A. J. (1966). Sémantique structurale. Paris: Hachette.

Huyghe, R. (1965). Les puissances de l' image. Paris: Flammarion.

Kerbrat-Orecchioni, C. (1990). Les interactions verbales. Tome I. Paris: Armand Colin. 
LIEB, I. C. (ed.). (1953). Ch. S. Peirce's Letters to Lady Welby. New Haven, Conn.: Whitlock's Inc.

LOTMAN, I. M. (1970). Lecții de poetică structurală (trad. în limba română). Bucuresti: Univers.

LotMAN, I. M. (1974). Studii de tipologie a culturii (trad. în limba română). București: Univers.

LOTMAN, I. M. (1976). «Un modèle dynamique des systèmes sémiotiques». En Travaux sur les systèmes des signes. École de Tartu, 129-137. Bruxelles: Complexe.

MARCUS, S. (ed.) (1985). Semnificație și comunicare în lumea contemporană. Bucuresti: Editura Politică.

Mukă̌ovsky I. (1974). Studii de estetică (trad. în limba română). București: Univers.

NEȚ, M. (1991). «Types d'interprétants du texte artistique-référent, symbole, topos, motif». En Semiotik Interdisziplinar II. Angewandte Semiotik 7, Jeff Bernard (hg.), 35-46. Wien: ÖGS.

- (1992). «Etapes de la sémiose peirceene». En Procedings of the $4^{\text {th }}$ Congress of the IASS/AIS, 1311-1317. Berlin: Mouton De Gruyter.

- (1995). «La lexicologie dans la perspective de la sémiotique peircienne». Studia Universitatis «Babes-Bolyai». Philologia, XL, 1, 5-19.

OEHLER, K. (1985). «Compendiu al semioticii lui Peirce». En Semnificație și comunicare în lumea contemporană. S. Marcus (ed.), 211-225. București: Editura Politică.

PARRET, H. (1983). Semiotics and Pragmatics. An Evaluative Comparison of Conceptual Frameworks. Amsterdam / Philadelphia: John Benjamins.

PeIRCE, Ch. S. (1931-1935). Collected Papers of Charles Sanders Peirce [C. P.], vol. 1-6. Cambridge, Mass.: Harvard University Press.

PeIrCE, Ch. S. (1955). Philosophical Writings of Peirce. Selected and edited with an Introduction by Justus Buchler. New York: Dover Publications Inc.

PetöFi, J. S. (ed.) (1979). Text vs. Sentence. Basic questions in text linguistics. Part 1 and 2. Hamburg: Buske.

- y OLIVI, T. (1989). «Understanding Literary Text». En Comprehension of Literary Discourse, D. Meutsch y R. Viehoff (eds.), 356378. Berlin, New York: Walter de Gruyter.

Platón (1979). Opere, vol. III (traducere de Simona Noica). București:

Editura Științifică și Enciclopedică.

Riffaterre, M. (1983). Sémiologie de la poésie. Paris: Seuil.

Scinto, L. F. M. (1983). «Functional Connecting and the Communicative

Structure of Text». En Micro and Macro Connexity of Text, J. Petöfi y E.

Sözer (eds.), 117-139. Hamburg: Buske.

STATI, S. (1990). Le transphrastique. Paris: PUF.

VASILIU, E. (1990). Introducere în teoria textului. București: Editura Știintifică și Enciclopedică.

VLAD, C. (1982a). Semiotica criticii literare. București: Editura Științifică și Enciclopedică. 
- (1982b). «Perceptive Levels in a Stratified Representation of Text». RRL XXVII, 4, 315-323.

- (2000). Textul aisberg. Elemente de teorie și analiză. Cluj: Casa Cărții de Știință. 